\title{
To B or not to B. The rationale for quantifying B-lines in paediatric lung diseases.
}

\author{
Niccolò Parri ${ }^{1}$, Marco Allinovi ${ }^{2}$, Martina Giacalone ${ }^{3}$, and Iuri Corsini ${ }^{2}$ \\ ${ }^{1}$ Azienda Ospedaliero Universitaria Ospedale Pediatrico Meyer \\ ${ }^{2}$ Azienda Ospedaliero Universitaria Careggi \\ ${ }^{3}$ Azienda Ospedaliero Universitaria Meyer
}

November 14, 2021

\begin{abstract}
The evaluation of the lung by ultrasound is an adjunct tool to the clinical assessment. Among different hallmarks at lung ultrasound, B-lines are well known artifacts which are not correlated to identifiable structures but can be used as an instrument for pathological classification. Multiple B-lines are the sonographic sign of lung interstitial syndrome with a direct correlation between the number of B-lines and the severity of the interstitial involvement of lung disease. In neonatology and paediatrics, the quantitative assessment of B-lines is questionable as opposed to in adult medical care. Counting B-lines is an attempt to enrich the clinical assessment and clinical information, and not simply arrive at a dichotomous answer. A semiquantitative or quantitative B-lines assessment was shown to correlate with fluid overload and demonstrated prognostic implications in specific neonatal and paediatric conditions. In neonatology, the count of B-lines is used to predict the need for admission in neonatal intensive care unit and the need for exogenous surfactant treatment. In paediatrics, the B-lines count has the role of quantifying hypervolemia in infants and children receiving dialysis. B-lines as predictors of length of stay in the paediatric intensive care unit after cardiac surgery, as a marker of disease severity in bronchiolitis, or as an indicator of lung involvement from SARS-CoV-2 infection are speculative and not yet supported by solid evidence. Lung ultrasound with the quantitative B-lines assessment is promising. The current evidence allows to use the quantification of B-lines in a limited number of neonatal and paediatric diseases.
\end{abstract}

\section{Hosted file}

Manuscript Ped Pulmonology.doc available at https://authorea.com/users/328554/articles/ 545381-to-b-or-not-to-b-the-rationale-for-quantifying-b-lines-in-paediatric-lungdiseases

\section{Hosted file}

Figue legends.doc available at https://authorea.com/users/328554/articles/545381-to-b-ornot-to-b-the-rationale-for-quantifying-b-lines-in-paediatric-lung-diseases

\section{Hosted file}

Table 1.doc available at https://authorea.com/users/328554/articles/545381-to-b-or-not-to-bthe-rationale-for-quantifying-b-lines-in-paediatric-lung-diseases 

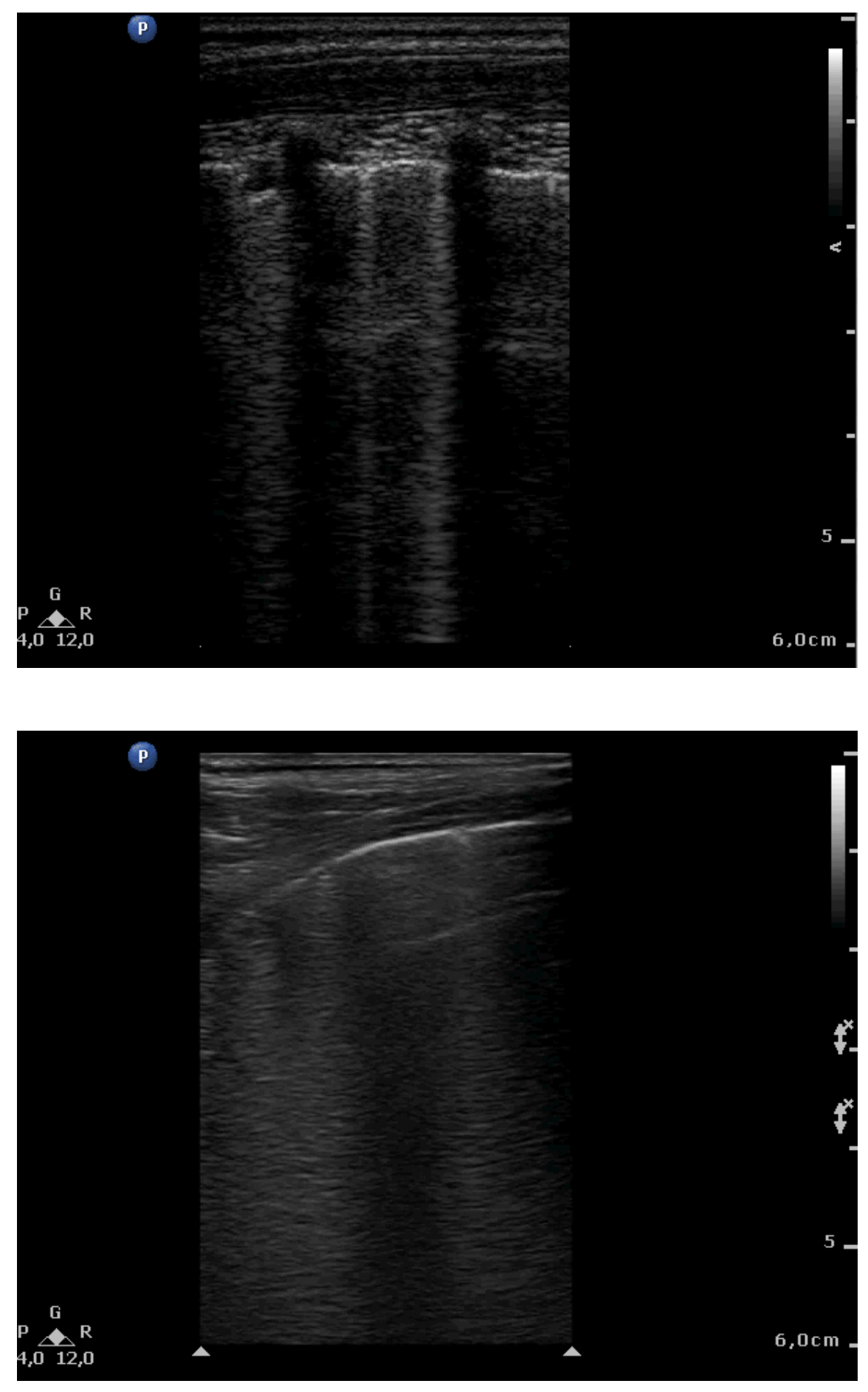

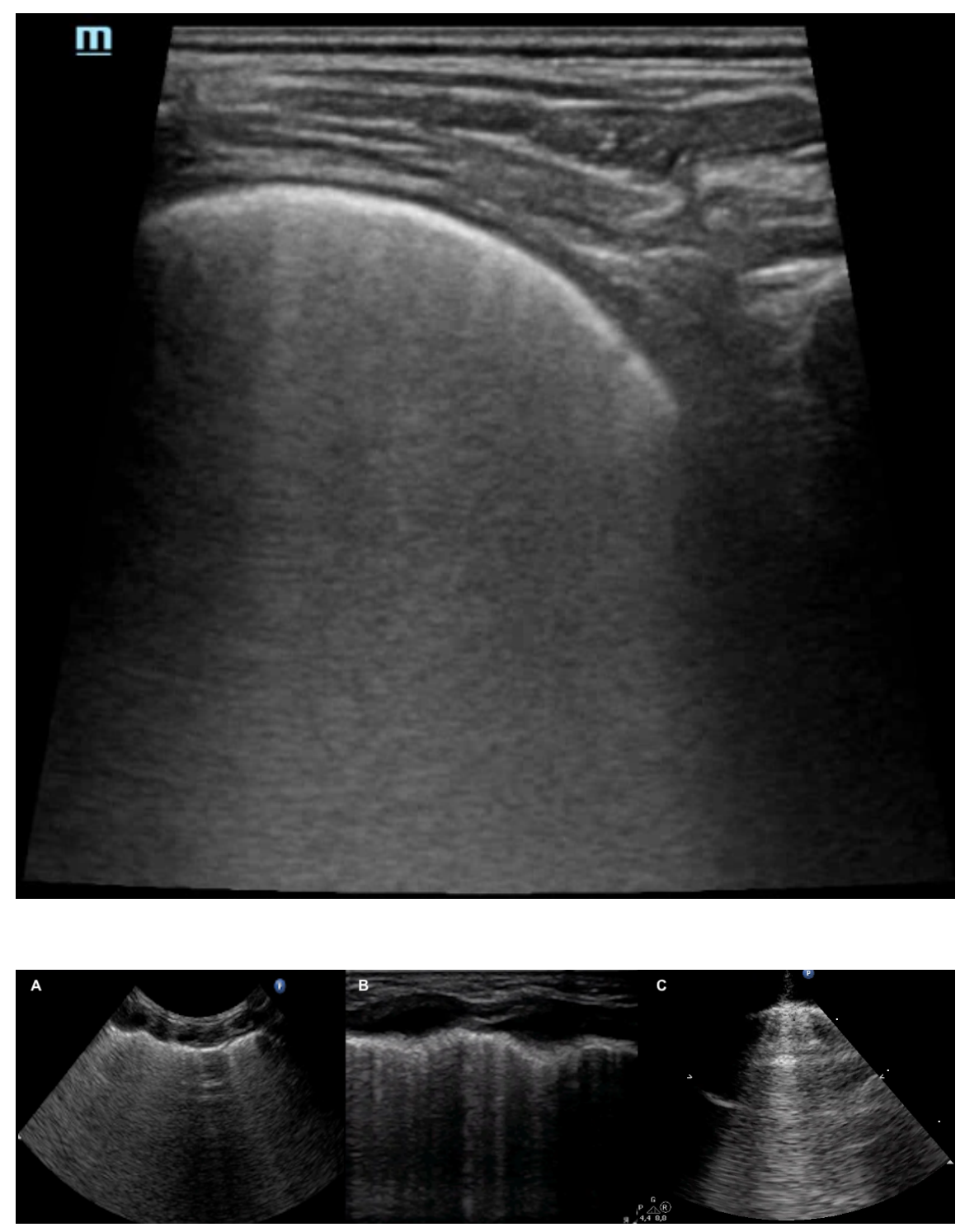

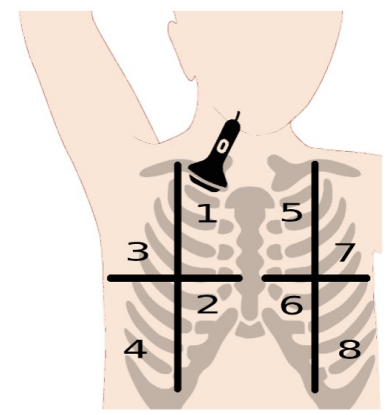

8-zones scan

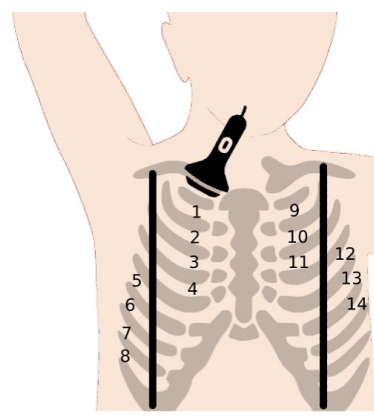

14-zones scan

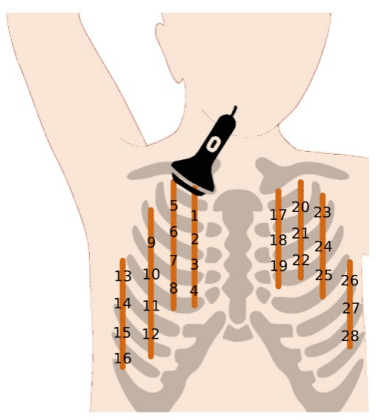

28-zones scan 

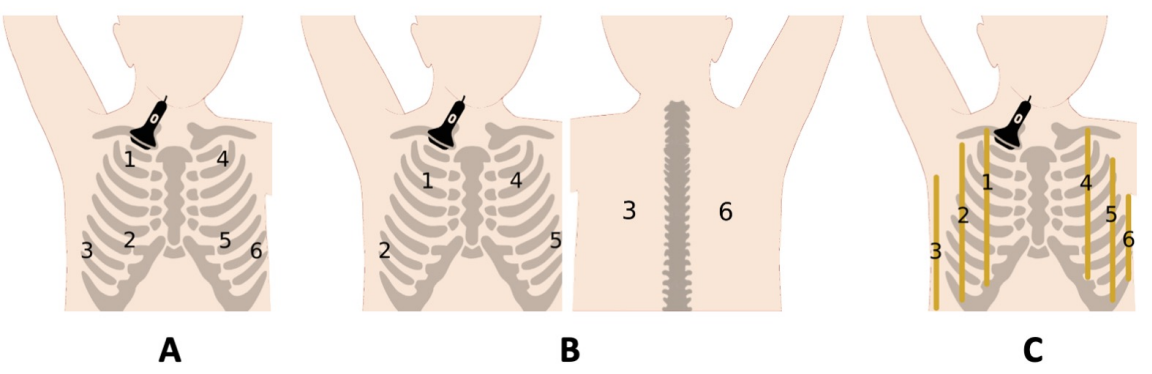